\title{
Laboratory Tests and FE Modeling of the Concrete Canvas, for Infrastructure Applications
}

\author{
Balázs Eller, Movahedi Rad Majid, Szabolcs Fischer
}

Széchenyi István University

Egyetem tér 1, H-9026 Győr, Hungary

\{eller.balazs,majidmr,fischersz\}@ sze.hu

\begin{abstract}
The Concrete Canvas (CC) material, is a promising material for application in many civil engineering fields, such as, water construction, pipelining, slope protection, military applications, etc. The authors believe that this material has more potential and could be helpful in infrastructure applications. The infrastructure design requirements are known; the CC has to be fit into the track structure. Several relevant investigations were performed to show the materials adequacy, and using collected data, FE (Finite Element) models were built to determine more of the physical parameters. From the results and the hardening experiences, it can be stated, that after the laying of CC and the spraying of water, the material has to be loaded to reach the best shape and push the material down to the supporting protection layer. In FE modeling, it was shown that the material is a composite structure, i.e. one material's physical properties is not enough for modeling (it has to be improved). Moreover, it means that dynamic examinations can be initiated.
\end{abstract}

Keywords: GCCM; ConcreteCanvas; railway; substructure; FE modeling

\section{Introduction}

The development of infrastructural technologies are continuous [1-4]. The new methods always solve exisiting problems, give more opportunities or costeffective solutions [5-8]. In this study, the authors also try to find solutions for drainage, adequate separation and strengthening. These problems can be a problem in road operation, too, but most problems occur in railways. Therefore, cost-effective technologies are needed, and it is especially true at the renewing of the local substructure problems. The local substructure problems mean a problem in a short section, for example, from 2 meters to 50-100 meters. The renewing of these cannot be done locally. Usually, it needs earthwork technology to renew the protection layer and the whole superstructure. If the drainage can't be handled, the problem will come back in a short time. The problems and the possible solutions were summarized in [9] [10]. 
The material which can allow us to improve these segments is the application of geosynthetic cementitious composite mats (GCCMs). The authors mainly investigate the most promising type of the GCCMs, the Concrete Canvas (CC). It was developed by Berwin and Crawford, in 2005. [11]. This technology until this time is mainly used in water construction, while it is an alternative solution for shotcrete. It is presented in several case studies, such as slope protection [12], a trackway for vehicles, pedestrians or a protection layer for pipe and lining [11]. Even so, the $\mathrm{CC}$ is barely investigated in the professional literature yet. The $\mathrm{CC}$ is available in 5, 8 and $13 \mathrm{~mm}$ thicknesses (CC5, CC8 and CC13, respectively). The mat is a cement-impregnated fabric. It contains a $3 \mathrm{D}$ fiber matrix with a special cement mixture, while the upper plane is a non-woven geotextile, and the lower plane is a PVC waterproofing layer [9]. The structure of the material can be seen in Fig. 1 (left). After it is hydrated by water, the material reaches high rigidity and strength according to the date scripts; it reaches $80 \%$ of the final physical properties. [13] [14].

The technology has drawbacks. For example, water access can be a problem, especially at railways, where access to the problematic section is nearly impossible on the road. In this case, an additional railway vehicle is required. In road construction, it is a much easier task.

The density of the CC at non-bound form is $1300-1500 \mathrm{~kg} / \mathrm{m}^{3}$ thanks to the dry cement powder in the structure. After the hydration, the final density increased by $25-30 \%$, to $1700-2000 \mathrm{~kg} / \mathrm{m}^{3}$. The density of the regular concrete is $2200-2400 \mathrm{~kg} / \mathrm{m}^{3}$ [11] [15].
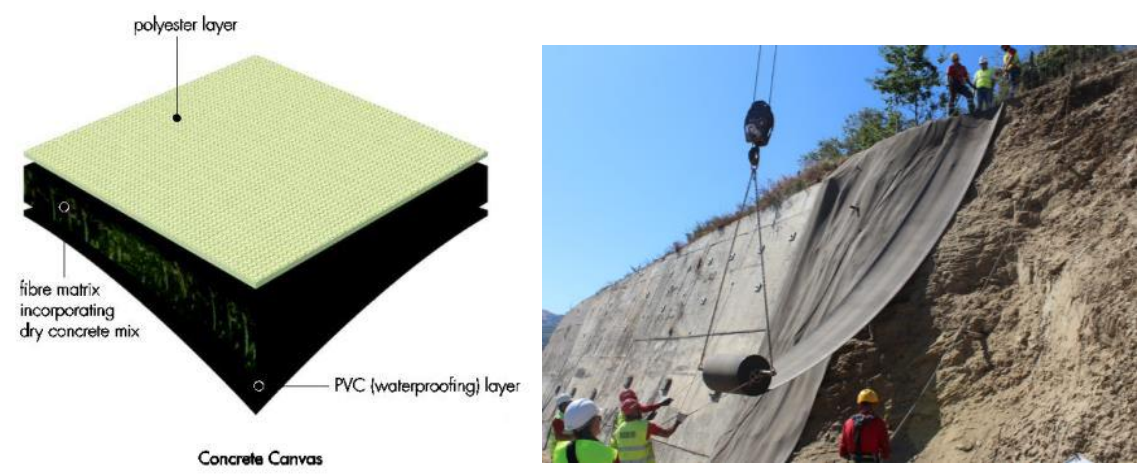

Figure 1

The structure and the application of CC [11]

In [16-18], the mechanical strength and the volume stability were described. The upper polyester layer has been woven in two directions. The longitudinal direction is more robust. The other variables are the type of the $3 \mathrm{D}$ fiber and the type/composition of cement. 
The material is a perfect solution for slope protection (Fig. 1, right), and several examinations were made, which gave good results. [19] [20] In place of the shotcrete layer, the CC hardens faster, and the properties are better or the same. The manufacturer shows several case studies on these topics [11]. Furthermore, thanks to its nearly waterproof property, the soil does not absorb water from the rain, so the moisture content does not generate problems.

This article aims to introduce the our laboratory investigations and, based on the results, draw any conclusions concerning the applications in infrastructure construction, mainly from railway aspects.

\section{Laboratory Examinations}

To examine the material's behavior at railway or road circumstances, we have to think about how much force (load) can occur on the material. First, the material has to deal with static loads. In the aspect of roads, the max. axle load is approx. $100 \mathrm{kN}$, while the max. axle loads at the railways are $225 \mathrm{kN}$ (in Hungary). Other countries use larger axle loads ( $250 \mathrm{kN}$ or more), but the authors investigate the Hungarian conditions primarily. On the other hand, the axle load is not the only load on the structure; the superstructure of the railway has its own dead load, too. But this dead load is appropriate to create the ideal plane of the CC layer on the protection layer. Among the types of material, the authors decided to investigate the $13 \mathrm{~mm}$ thick material because in this kind and amount of loading, the thicker is the better choice.

Suppose the static loads cannot occur problems in the material, and the physical properties give a continuously appropriate layer. The second step is to investigate the material for dynamic loads. The load distribution at the railways is particular; it spreads by a nominal degree of $45^{\circ}$ (see Fig. 2).

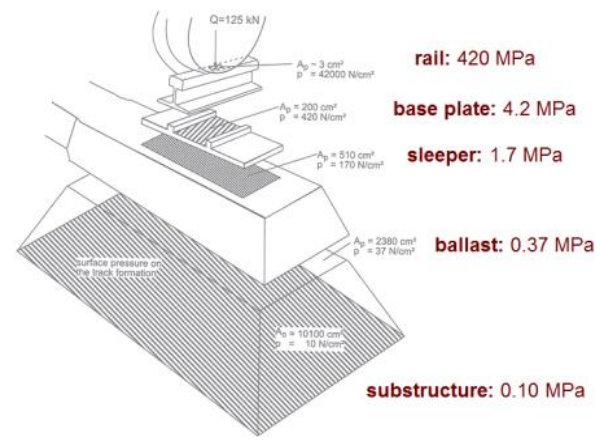

Figure 2

Load distribution at railways [21] 
In the professional literature, several tests were shown in [12-15, 18, 22, 23], like puncture test, 3-point bending test, tensile test, etc. We studied and tried the different tests, and finally, the authors selected the following relevant static laboratory tests:

- $\quad$ Four-point bending test (in place of three-point bending test)

- Compressive strength test

- Puncture test

\subsection{Four-Point Bending Test}

According to previous experiences, the 4-point bending test was chosen in place of the three-point test because shear loads were occurring at the latter test. It could be complicated at the finite element modeling (FEM). 350×200 mm samples were cut from CC13, and these were divided into three $100 \mathrm{~mm}$ sections. The illustration of this test can be seen in Fig. 3 (left and right). The movement (displacement) of the edges was measured in the middle; blue arrows signed it.

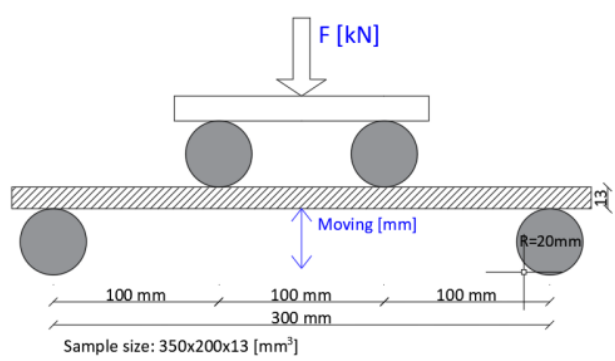

Figure 3

Four-point bending test

\subsection{Compressive Strength Test}

Compressive strength tests were not found in the authors' research, so this test was planned based on our ideas. The unique cement powder mixture was not available for the authors, so they had to think of another way to measure the compressive strength and calculate the material's Young's modulus. Finally, it was decided to cut $300 \times 300 \mathrm{~mm}$ size tables from CC13. The material was loaded slowly until $200 \mathrm{kN}$. The movement was measured in every corner, and then the average movement (displacement) was calculated from the four values. The illustration of this test can be seen in Fig. 4 (left and right). Another essential part is the making of the samples. The $\mathrm{CC}$ has to be covered with weight after hydration. If not, the material can be 'wavy', which can be a problem at the test. 
If the surface is not flat and one or two corner bends up, the result of the average movement can be larger than the real value, so false values can be received. If these columns of data are deleted, the average would not be so accurate.
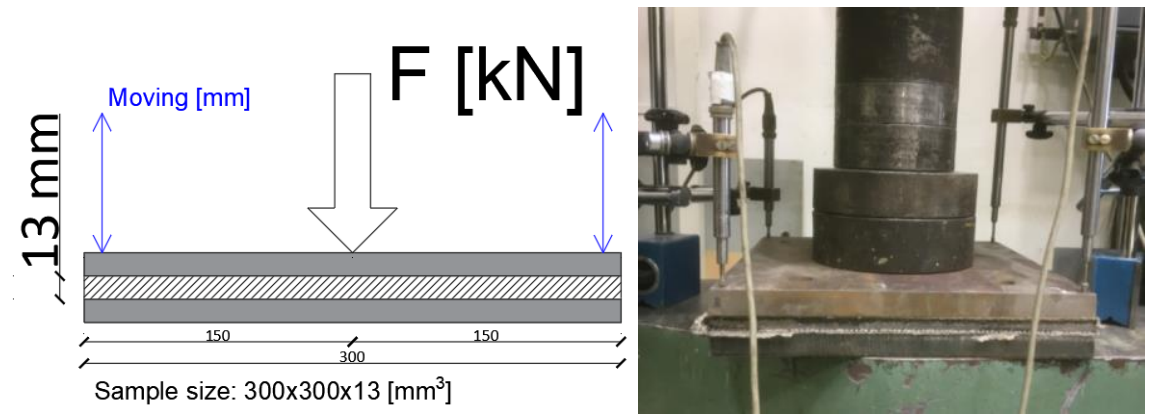

Figure 4

Compression strength stress

\subsection{Puncture Test}

This test was performed according to the concerning ISO standard [24] (see Figs. 5 and 6). In [13], puncture tests were executed on GCCM materials. This test is usable at modeling real circumstances when there is no support under the CC layer (especially at railways, at local failures). At this test $250 \times 250 \mathrm{~mm}^{2}$ samples were cut, and these were fixed to two circle profiles, with a minimum diameter of 150 $\mathrm{mm}$. The material got no lower support, while a $50 \mathrm{~mm}$ diameter plunger loaded it. The material was loaded until the first crack, and then it was loaded continuously until the textile and the PVC layer were also torn.
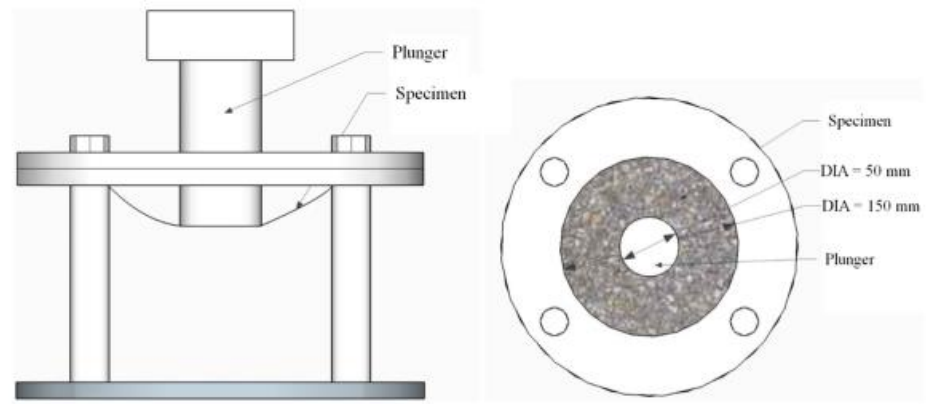

Figure 5

Puncture test [5] 

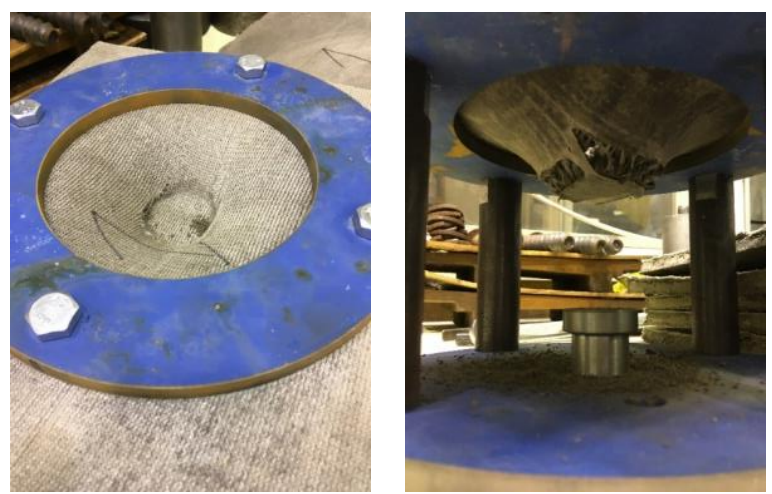

Figure 6

The deformation after the puncture test

\section{Results}

\subsection{Four-Point Bending Test}

According to the manufacturer's data script (datasheet), the initial break occurs at $>4 \mathrm{MPa}$, while the final break occurs at $>6 \mathrm{MPa}$ [25]. Compared to the measured data, the authors determined lower stress until the initial break. The measured results can be seen in Table 1. It can be observed that the direction of the woven makes a difference in the stress of the initial break. On the other hand, the bending stress does not reach $80 \%$ after 24 hours, while the deflection is larger than the hardened types. It is because the material is plastic at this time. Because of this plastic behavior, the $\mathrm{CC}$ takes the shape of the lower plane of the ballast bed [25].

It can be seen in Table 1 that there is constant stress increasing at the longitudinal direction, while at the transversal direction, the 7-day samples were more rigid and robust than the 28-day samples. It is probably the problem of hydration; if the water spraying is not even, the rigidity of the CC layer will not be the same at every point. Thanks to this, the standard deviation is quite significant. The table also shows that the bending was between $0.51-1.10 \mathrm{~mm}$ in every case, which is a tiny difference.

The calculated data are low values. If Fig. 2 is rechecked, it can be noticed that the nominal/assumed load on the plane of the protection layer is only $0.1 \mathrm{MPa}$ (with $250 \mathrm{kN}$ axle load and without deadweight, which is negligible compared to the axle load). Of course, it is not accurate and different in real, because the distribution of the loads is going through ballast particles, but it is suitable for 
illustration. One day after the hydration, the lowest bending stress is much larger than the loading on the plane of the protection layer. The support under the CC layer is assumed to be continuous and adequate, so the breakage will not happen predictably.

Table 1

Results of the four-point bending test

\begin{tabular}{|c|c|c|c|c|c|c|}
\hline & Stress [Mpa] & Woven & & Stress $[\mathrm{MPa}]$ & Woven & Diff. \\
\hline \multicolumn{7}{|c|}{ Results after 1 day } \\
\hline Average: & 3.01 & \multirow{3}{*}{ longitudinal } & Average: & 2.15 & \multirow{3}{*}{ transversal } & \multirow{3}{*}{$37.2 \%$} \\
\hline Standard dev.: & 0.05 & & Standard dev.: & 0.02 & & \\
\hline Difference [\%]: & 17.75 & & Difference [\%]: & 7.20 & & \\
\hline \multicolumn{7}{|c|}{ average deflection until the first crack: 0.73 and 0.51} \\
\hline \multicolumn{7}{|c|}{ Results after 7 day } \\
\hline Average: & 5.60 & \multirow{3}{*}{ longitudinal } & Average: & 3.87 & \multirow{3}{*}{ transversal } & \multirow{3}{*}{$38.3 \%$} \\
\hline \begin{tabular}{|l|} 
Standard dev.: \\
\end{tabular} & 0.13 & & Standard dev.: & 0.07 & & \\
\hline Difference [\%]: & 27.07 & & Difference [\%]: & 16.70 & & \\
\hline \multicolumn{7}{|c|}{ average deflection until the first crack: 0.63 and 0.63} \\
\hline \multicolumn{7}{|c|}{ Results after 28 day } \\
\hline Average: & 7.83 & \multirow{3}{*}{ longitudinal } & Average: & 2.38 & \multirow{3}{*}{ transversal } & \multirow{3}{*}{$229.5 \%$} \\
\hline Standard dev.: & 0.15 & & \begin{tabular}{|l} 
Standard dev.: \\
\end{tabular} & 0.08 & & \\
\hline Difference [\%]: & 19.48 & & Difference [\%]: & 32.14 & & \\
\hline
\end{tabular}

Using the received and the given data, the examination model was built (Fig. 7). Without knowing the correct material parameters, the authors used the calculated Young's modulus from the compression test. The results were not the same on the model and from the laboratory measurements. The experience is that only Young's modulus is not enough to build the material model because unreal ending values were obtained. On the other hand, the bending results were not the same at the different woven directions, which also occurs some problem at the illustration of the correct movement. In Fig. 7, it can be seen a sample with a weaving of the longitudinal direction. The average load was given, while the Young's modulus was from the compression test. The deflection is nearly $8 \mathrm{~mm}$, while the average movement (displacement) until the first break was $1.1 \mathrm{~mm}$.

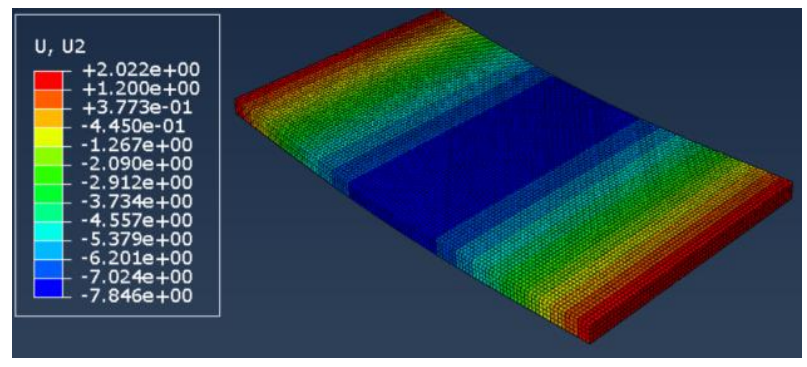

Figure 7

The model of the four-point bending test 
It can be stated that the model needs more parameters; on the other hand, a new composite structure with different parameters had to be built. The concrete layer is only $11 \mathrm{~mm}$ of the $13 \mathrm{~mm}$ total thickness, so only the concrete parameters will show false results.

\subsection{Compressive Strength Test}

The measuring of the compressive strength is important because it was needed to determine the material's Young's modulus. The data obtained are plotted on a graph, and then the load section where the chart has the most significant slope is selected. After that, using the "least squares" method, a straight line was calculated that best fits the data, and then returned an array that described the line was returned. From that, the Young's modulus was able to be received, which can be seen in Table 2. The first problem is the high standard deviation. As it was mentioned earlier in Chapter 3.1, the problem can be unequal hydration.

Table 2

Results of the compression test

\begin{tabular}{|c|c|c|c|}
\hline 1 days & $150 \mathrm{kN}$ - end [Mpa] & 28 days & $150 \mathrm{kN}$ - end [Mpa] \\
\hline $1120 / 1$ & 346.054 & $1218 / 1$ & 515.301 \\
\hline $1120 / 2$ & 736.230 & $1218 / 2$ & 495.089 \\
\hline $1120 / 3$ & 592.656 & $1218 / 3$ & 480.585 \\
\hline $1120 / 4$ & 303.246 & $1218 / 4$ & 507.845 \\
\hline $1120 / 5$ & 328.415 & $1218 / 5$ & 645.734 \\
\hline $1120 / 6$ & 422.053 & $1218 / 6$ & 733.183 \\
\hline $0520 / 1$ & 444.889 & $0615 / 1$ & 419.886 \\
\hline $0520 / 2$ & broken & $0615 / 2$ & 424.524 \\
\hline $0520 / 3$ & 367.083 & $0615 / 3$ & 489.860 \\
\hline 0520/4 & 785.690 & & \\
\hline Average & 480.702 & Average & 523.556 \\
\hline \multicolumn{2}{|c|}{$\mathrm{E}=480.7 \mathrm{Mpa}$} & \multicolumn{2}{|c|}{$\mathrm{E}=523.6 \mathrm{Mpa}$} \\
\hline Stand. Dev. & 180.724 & Stand. Dev. & 102.184 \\
\hline Diff. [\%] & 38.092 & Diff. [\%] & 18.207 \\
\hline \multicolumn{4}{|c|}{ Calculation with full thickness } \\
\hline
\end{tabular}

The results were used at modeling (see Fig. 8) to check the correlation between the calculated data and the measured compression. The average compression at the measurements was $1 \mathrm{~mm}$. Using the calculated Young's modulus at the modeling, the received compression was not the same as the laboratory measurements. The result of the modeling was $0.028 \mathrm{~mm}$ as opposed to the $1 \mathrm{~mm}$ average compression. The problem can be found at the layer structure, again. The upper $\sim 1 \mathrm{~mm}$ woven textile and the lower $\sim 1 \mathrm{~mm}$ PVC layer can be compressed easier, but on the other hand, this $2 \mathrm{~mm}$ means $15.4 \%$ of the 
structure's thickness. These thin layers cannot be removed. One solution is to build the composite model structure from the three materials, but the validation can again be a problem at the two thin layers. The second solution is checking the shorter range in the elongation and loading graph, which could improve the received ' $E$ '. But in this case, while the material could be more robust, the compression will be lower. In our opinion, both solutions need to be used to make this test result more correct.

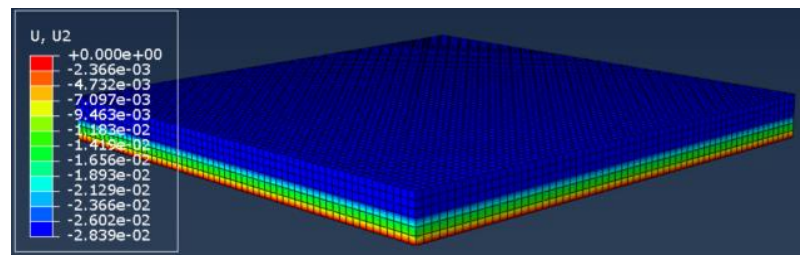

Figure 8

Modeling of the compression test

However, these tests were not successful from modeling; it was helpful to see that the CC layer is not being broken under the high load. It means that it can handle the static loads which are being occurred under the railway structure.

\subsection{Puncture Test}

According to the loadings of Fig. 1 and the test results, the puncture at operation circumstances can only happen in special cases; usually, the material is strong enough to support the railway superstructure and the static loads.

Table 3

Results of the puncture test

\begin{tabular}{|c|c|c|c|c|c|c|c|c|c|c|c|}
\hline \multicolumn{12}{|c|}{ Puncture test } \\
\hline \multicolumn{4}{|c|}{1 day after hydration } & \multicolumn{4}{|c|}{7 days after hydration } & \multicolumn{4}{|c|}{28 days after hydration } \\
\hline \# & Stress [Mpa] & Average & Stand.dev. & $\#$ & Stress [Mpa] & Average & Stand.dev & $\#$ & Stress [Mpa] & Average & Stand.dev. \\
\hline 1. & 0.976 & \multirow{6}{*}{0.927} & \multirow{7}{*}{0.043} & 1. & 1.388 & \multirow{7}{*}{1.135} & \multirow{7}{*}{0.227} & 1. & 0.916 & \multirow{7}{*}{1.170} & \multirow{7}{*}{0.230} \\
\hline 2. & 0.904 & & & 2. & 1.349 & & & 2. & 1.392 & & \\
\hline 3. & 0.896 & & & 3. & 1.081 & & & 3. & 1.547 & & \\
\hline 4. & 0.886 & & & 4. & 1.211 & & & 4. & 1.043 & & \\
\hline 5. & 0.986 & & & 5. & 1.239 & & & 5. & 1.116 & & \\
\hline \multirow[t]{4}{*}{6.} & 0.916 & & & 6. & 0.799 & & & 6. & 1.212 & & \\
\hline & & & & 7. & 0.877 & & & 7. & 0.965 & & \\
\hline & & $\begin{array}{l}\text { Standard } \\
\text { dev. [\%] }\end{array}$ & 4.619 & & & $\begin{array}{l}\text { Standard } \\
\text { dev. [\%] }\end{array}$ & 19.990 & & & $\begin{array}{l}\text { Standard } \\
\text { dev. [\%] }\end{array}$ & 19.698 \\
\hline & \multicolumn{3}{|c|}{ Hardened: $79.23 \%$} & \multicolumn{4}{|c|}{ Hardened: $97.01 \%$} & \multicolumn{4}{|c|}{ Hardened: $\mathbf{1 0 0 \%}$} \\
\hline
\end{tabular}

In Table 3, the results are shown. The values marked in grey are the stresses at which the first crack occurred. The marked values typically happen at a deflection of 9-11 mm; at this point, the concrete layer breaks. Regardless of the hardening, 
only the non-woven textile and the PVC layer holds the structure together, after the first crack. Up to an average value of $1.59 \mathrm{MPa}$, the PVC layer does not rupture, which typically means an elongation of $45-50 \mathrm{~mm}$. Until this point, the CC layer is still watertight.

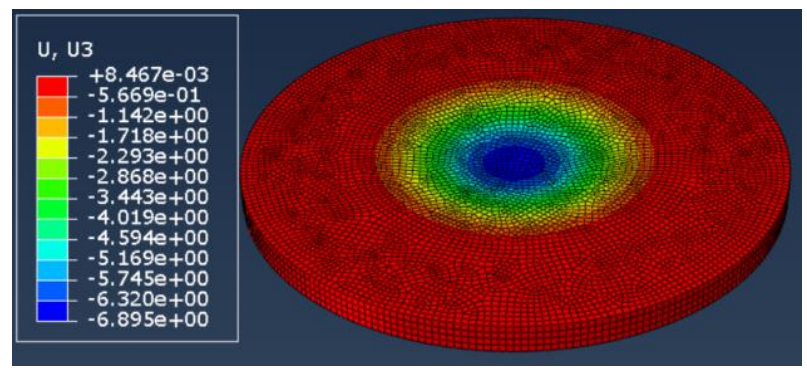

Figure 9

Modeling of the puncture test

The modeling showed a deflection of $\sim 6.9 \mathrm{~mm}$. At the measurement, the authors received the max. stress which eliminates the resistance of the concrete in the structure. This value is an appropriate average value because the mentioned 9-11 $\mathrm{mm}$ deflection does not mean the first break in the sample. It was mentioned at the compression test that more correct properties have to be determined. After that, the appropriateness of the just received value can be checked.

In the future (similar during dynamic and field tests, and FE modeling) the effect of sharp stones onto the $\mathrm{CC}$ material has to be considered and modeled.

\section{Conclusions}

The CC is easy to handle, conversly, water access, at the railways can cause problems. Therefore, the hydration of the material is very variable, which statement is determined by the standard deviation of the test results. According to the results, the $20 \%$ standard deviation is nearly normal for this type of material.

From the results and the hardening experiences mentioned in Chapter 2.2, it can be stated that after the application of $\mathrm{CC}$ and the spraying of water, the material has to be loaded to reach the best shape and push the material down to the supporting protection layer.

In the FE modeling, it could be seen that this type of material is a composite structure, so using only one material's physical properties is not enough. Therefore, for accurate and useful modeling, the structure materials have to be investigated separately.

According to the results of our examinations, the $\mathrm{CC}$ material is appropriate to give support during the static loads in railway infrastructure applications. Moreover, it means that the prepared dynamic examinations can be started. 


\section{Acknowledgement}

This work was supported by Concrete Canvas Ltd.

\section{References}

[1] M. Kurhan, D. Kurhan, R. Novik, S. Baydak, N. Hmelevska, Improvement of the railway track efficiency by minimizing the rail wear in curves. IOP Conference Series: Materials Science and Engineering, Vol. 985, No. 1, 2020, 012001

[2] M. Sysyn, U. Gerber, O. Nabochenko, V. Kovalchuk, Common crossing fault prediction with track based inertial measurements: Statistical vs. Mechanical approach, Pollack Periodica, Vol. 14, No. 2, 2019, pp. 15-26

[3] A. J. Tigh Kuchak, D. Marinkovic, M. Zehn,, Finite element model updating - Case study of a rail damper. Structural Engineering and Mechanics, Vol. 73, No. 1, 2020, pp. 27-35

[4] U. Gerber, M. Sysyn, J. Zarour, O. Nabochenko, Stiffness and strength of structural layers from cohesionless material. Archives of Transport, Vol. 49, No. 1, 2019, pp. 59-68

[5] A. Kampczyk, K. Dybel, The fundamental approach of the digital twin application in railway turnouts with innovative monitoring of weather conditions. Sensors, Vol. 21, No. 17, 2021, 5757

[6] A. Matejov, J. Šestáková, The Experiences with utilization of BIM in railway infrastructure in Slovak Republic and Czech Republic. Transportation Research Procedia, Vol. 55, 2021, pp. 1139-1146

[7] A. Németh, S. Fischer, Investigation of glued insulated rail joints applied to CWR tracks. Facta Universitatis-Series Mechanical Engineering, 2021, 7642

[8] S. Fischer, Investigation of effect of water content on railway granular supplementary layers. Naukovyi Visnyk Natsionalnoho Hirnychoho Universytetu, No. 3, 2021, pp. 64-68

[9] B. Eller, S. Fischer, Review of the modern ballasted railway tracks' substructure and further investigations. Nauka ta Progres Transportu, Vol. 84, No. 6, 2019, pp.72-85

[10] B. Eller, S. Fischer, Tutorial on the emergence of local substructure failures in the railway track structure and their renewal with existing and new methodologies. Acta Technica Jaurinensis, Vol. 14, No. 1, 2021, pp. 80-103

[11] Concrete Canvas Ltd. https://www.concretecanvas.com [online, last visited on: 2021.10.15]

[12] H. Li, H. Chen, X. Li, F. Zhang, Design and construction application of concrete canvas for slope protection. Powder Technology, Vol. 344, 2018, pp. $937-946$ 
[13] T. Jirawattanasomkul, N. Kongwang, P. Jongvivatsakul, S. Likitlersuang, Finite element analysis of tensile and puncture behaviours of geosynthetic cementitious composite mat (GCCM) Composites Part B, Vol. 154, 2018, pp. 33-42

[14] P. Jongvivatsakul, T. Ramdit, P. T. Ngo, S. Likitlersuang, Experimental investigation on mechanical properties of geosynthetic cementitious composite mat (GCCM) Construction and Building Materials, Vol. 166, 2019, pp. 956-965

[15] F. Zhang, H. Chen, X. Li, H. Li, T. Lv, W. Zhang, Y. Yang, Experimental study of the mechanical behavior of FRP-reinforced concrete canvas panels. Composite Structures, Vol. 176, 2017, pp. 608-616

[16] F. Han, H. Chen, X. Li, B. Bao, T. Lv, W. Zhang, W. Hui Duan, Improvement of mechanical properties of concrete canvas by anhydritemodified calcium sulfoaluminate cement. Journal of Composite Materials, Vol. 50, No. 14, 2015, pp. 1937-1950

[17] F. Han, H. Chen, W. Zhang, T. Lv, Y. Yang, Influence of 3D spacer fabric on drying shrinkage of concrete canvas. Journal of Industrial Textiles, Vol. 45, No. 6, 2016, pp. 1457-1476

[18] Han, F., Chen, H., Jiang, K., Zhang, W., Lv, T., \& Yang, Y. (2014) Influences of geometric patterns of 3D spacer fabric on tensile behavior of concrete canvas. Construction and Building Materials, 65, 620-629

[19] H. Li, H. Chen, L. Liu, F. Zhang, F. Han, T. Lv, W., Zhang, Y. Yang, Application design of concrete canvas (CC) in soil reinforced structure. Geotextiles and Geomembranes, Vol. 44, No. 4, 2016, pp. 557-567

[20] H. Li, H. Chen, X. Li, F. Zhang, Design and construction application of concrete canvas for slope protection. Powder Technology, Vol. 344, 2019, pp. 937-946

[21] S. Fischer, B. Eller, Z. Kada, A. Németh, Railway Construction (lecture note). Széchenyi István University, Faculty of Architecture, Civil- and Transport Engineering, Department of Transport Infrastructure, 2015

[22] T. Jirawattanasomkul, N. Kongwang, P. Jongvivatsakul, S. Likitlersuang, Finite element analysis of tensile and puncture behaviours of geosynthetic cementitious composite mat (GCCM) Composites Part B: Engineering, Vol. 165, 2019, pp. 702-711

[23] F. Han, H. Chen, W. Zhang, T. Lv, Y. Yang, Influence of 3D spacer fabric on drying shrinkage of concrete canvas. Journal of Industrial Textiles, Vol. 45, No. 6, 2016, pp. 1457-1476

[24] ISO 12236:2006 Geosynthetics - Static puncture test (CBR test)

[25] European Technical Assessment (2019) ETA-19/0086 of 22/03/2019 